\title{
Influential factors on the oil agglomeration process for coal recovery from different grade coals
}

\author{
Q. Wang ${ }^{1}$, H. Niida ${ }^{1}$, P. Apar ${ }^{1}$, Q. Chen $^{1}$, L. Gui ${ }^{1}$, Q. Qian ${ }^{1}$, \\ N. Mitsumura ${ }^{1}$, H. Kurokawa ${ }^{1}$, K. Sekiguchi ${ }^{1} \&$ K. Sugiyama ${ }^{2}$ \\ ${ }^{I}$ Department of Environmental Science and Technology, \\ Graduate School of Science and Engineering, Saitama University, Japan \\ ${ }^{2}$ Hachinohe National College of Technology, Japan
}

\begin{abstract}
Large amounts of waste fine coals are produced, which are difficult to be treated because of high ash content and inorganic sulfuric compounds. In order to make efficient use of waste fine coal, a retrieval technique is necessary for the recovery of coal combustible content from fine waste coals. Nowadays, the floatation process can be used, but it is impractical for developing countries due to high costs, then the oil agglomeration process can deal with these problems. In this study, we investigated the affecting factors of coal cleaning efficiency of oil agglomeration on the element content and chemical structure of three different grade coals because there are many grades of coals around the world.

For determination of chemical content in three different grade coals, the help of proximate and ultimate analysis was used, and then for investigation of their chemical structure differences of carbonaceous content, a Fourier transforminfrared spectrometry (FT-IR) was applied. Furthermore, for the oil agglomeration experiments, kerosene and vegetable oil which differ in structure were used as aggregating agents. We used ash free coals or their mixed samples which were conditioned to the ratios of carbonaceous and ash content in order to make it the same contained amounts.

From the results of the oil agglomeration experiments, it was concluded that the characteristics of agglomerate and the coal cleaning efficiency of oil agglomeration are not only influenced by the oil types, but also affected by the oxygenic content, aromatic and aliphatic chemical structures in different grade coals. Oxygenic function groups of carbonaceous content in coal samples
\end{abstract}


prevent oil from attaching to the carbonaceous surface and forming the bulky aggregate. Then, it leads to depressing combustible matter recovery; however, this can be improved by changing oil types. Oxygenic content in oil such as vegetable oil plays the role of the bridging material to the oxygenic function groups of carbonaceous content in coal samples. Moreover, the aromatic functional groups in carbonaceous content have the resonance inspection of delocalized $\pi$ electrons; it interacts badly to the aliphatic functional groups in oil. Comparatively carbonaceous content consisting of more aliphatic series tends to form aggregates easily. Whatever coals we use on the oil agglomeration, it is possible to achieve better efficiency by taking these factors into account.

Keywords: oil agglomeration, waste fine coal, Fourier transform-infrared spectrometry (FT-IR), hydrophobicity, aliphatic and aromatic content, ash.

\section{Introduction}

Coal production increases continuously due to the increase in mechanization in coal mining and demand in its related fields of application worldwide. Especially, in China where the coal production trend is increasing and large amounts of waste fine coals $(<500 \mu \mathrm{m})$ are produced, which are hard to be treated because they have a lot of ash content and inorganic sulfurs. Accordingly, waste fine coals are difficult to be available as a resource and cause spontaneous combustion leading in turn to air pollution, land occupation, soil pollution and water contamination [1]. In order to make efficient use of waste fine coals, the retrieval technique is necessary for recovery of the combustible content of coals from waste fine coals. The floatation process can treat these, but there are problems of operating costs in developing countries. At present, oil agglomeration has attracted attention in the way of dealing with this problem. The oil agglomeration process is a coal cleaning method used for differences of surface characteristics between carbonaceous and ash content [2]. Hydrophobic oil which is an aggregating agent selectively attaches to hydrophobic carbonaceous content and forms the agglomerate. From the difference of particle size between aggregate and ash content (figure 1), we can only recover carbonaceous content and remove ash content [3,4]. From our previous experiments of different particle sizes, we only succeeded in recovering coal combustible carbonaceous content from waste coals [5].

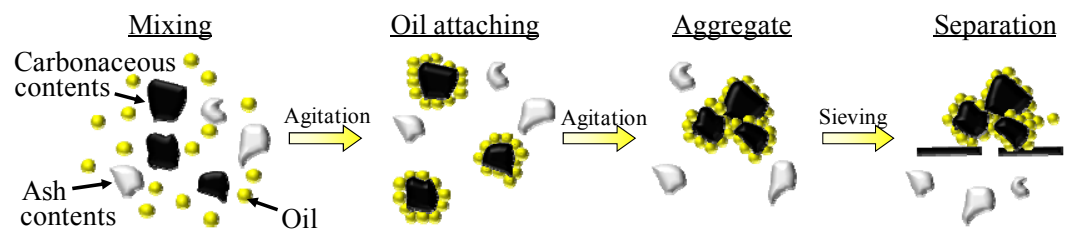

Figure 1: $\quad$ Principle and concept of oil agglomeration for coal cleaning.

In the oil agglomeration experiments, the optimum condition has been looked for in various studies, such as a parameter as agitating time or speed, the type or concentration of aggregating agent, the addition of the electrolyte to water 
solvent [5-8]. As a result, the main objective is the recovery of combustible matter, removing the ash and sulfur content, but the optimum condition only has a beneficial effect on a coal which was used in the experiments. In the world, there are many types of coals and some of these are difficult to be recovered based on oil agglomeration because these coals have a characteristic which is different from each other. In general, it is said that the coals are classified as anthracite coal, bituminous coal, brown coal and peat. The lower the grade, the less carbon content and calorific valve there is, in comparison, the low grade coal has a lot of oxygenic content which is hydrophilic [8]. The increasing oxygenic function groups of carbonaceous content may contribute to it being more hydrophilic, prevent oil which is hydrophobic from attaching to the carbonaceous surface, eventually depressing the coal cleaning efficiency. For being turned into the actual utilization of oil agglomeration process, the development of the process has to be compatible with the type of coals because it may be impossible for recovered waste coals to have the same surface feature and chemical structure of carbonaceous content. In this study, we investigated the factors of affecting coal cleaning efficiency on the oil agglomeration with three different grade coals varied element content and chemical structure of carbonaceous content.

\section{Experimental procedures}

\subsection{Sample preparation}

As samples of the different grade coals, Chongqing coal, Furong coal of China and Adaro coal of Indonesia were selected as differed grades of anthracite coal, bituminous coal and lignite coal, respectively. Different coal samples were mired and the particle sizes of these samples were screened to about 53-75 $\mu \mathrm{m}$ by adjustment using several sieves. The proximate and ultimate analyses of coal samples were measured according to the Japanese industrial standard (JIS) method of JIS-M8812.

The results of proximate analysis and ultimate analysis of coal samples are shown in table 1 . It is revealed that the ratios of ash content indicate different values from proximate analysis and the ratios of oxygenic content are higher in

Table 1: $\quad$ Results of proximate and ultimate analysis.

\begin{tabular}{|c|c|c|c|c|c|c|c|c|c|}
\hline \multirow{2}{*}{$\begin{array}{c}\text { Coal } \\
\text { sample }\end{array}$} & \multicolumn{4}{|c|}{ Proximate analysis (wt.\%) } & \multicolumn{5}{|c|}{ Ultimate analysis (wt.\%) } \\
\hline & Ash & $\mathrm{M}$ & $\mathrm{VM}$ & FC & $\mathrm{C}$ & $\mathrm{H}$ & $\mathrm{N}$ & $\mathrm{O}$ & $\mathrm{S}$ \\
\hline Chongqing & 11.9 & 2.4 & 18.9 & 66.8 & 90.7 & 4.7 & 1.6 & 3.0 & 0.045 \\
\hline Furong & 24.8 & 3.1 & 15.2 & 56.9 & 80.0 & 4.0 & 1.5 & 10.5 & 4.0 \\
\hline Adaro & 3.3 & 9.3 & 45.7 & 41.7 & 62.4 & 5.3 & 1.1 & 31.5 & 0.11 \\
\hline
\end{tabular}

M: moisture, VM: volatile matter, FC: fixed carbon. 
the order corresponding to Adaro coal, Furong coal and Chongqing coal from proximate analysis. The volatile matter of Chongqing coal consisting of $90 \%$ carbon content and 3\% oxygenic content is high, which indicated that coal samples need to be investigated in detail constitutionally.

\subsection{Acid digestion treatment of mineral substances from raw coal samples}

In order to prepare ash free coal samples, the coal samples needed to undergo acid digestion treatment. And then, we can adjust the ratios of carbonaceous and ash content for the oil agglomerating process. The acid solutions of $\mathrm{HCl}$ and $\mathrm{HF}$ are used respectively in the method of acid digestion treatment which can reduce ash content to prepare ash free coal samples [9]. Therefore, Adaro is not treated in this way because of it has enough low ash content. The $\mathrm{HCl} / \mathrm{HF}$ acid digestion treatment procedure is presented in table 2. The indicated mass of coals was treated in the listed number of hours in the aqueous $\mathrm{HCl}$ solutions (Step 1). The remaining coals were filtered and washed with tap water and ultrapure water to remove $\mathrm{HCl}$ acid until the $\mathrm{pH}$ was 7.0. Step 2 of the $\mathrm{HF}$ acid digestion treatment procedure was performed similarly to Step 1, but in a Teflon beaker. After filtering and washing, the $\mathrm{HCl}$ acid digestion treatment procedure (Step 3) was conducted. Then the acid treated coal was similarly washed to remove the remaining acid, searched on the way of the proximate analysis. Table 3 shows the analytical results of acid digestion treatment, the ash content of acid treated coal samples decreases by about 3.0\%. Here, Chongqing coal and Furong coal by acid digestion treatment and original Adaro raw coal were called 'ash free coals', used in the analysis of chemical structure and oil agglomeration experiments.

Table 2: $\quad$ Experimental conditions of acid digestion treatment for free ash.

\begin{tabular}{|c|c|c|c|c|c|c|c|}
\hline \multirow{3}{*}{$\begin{array}{c}\text { Coal } \\
\text { sample }\end{array}$} & \multirow{3}{*}{$\begin{array}{l}\text { Coal } \\
\text { Mass } \\
\text { (g) }\end{array}$} & \multicolumn{2}{|c|}{ Step 1} & \multicolumn{2}{|c|}{ Step 2} & \multicolumn{2}{|c|}{ Step 3} \\
\hline & & $\mathrm{HCl}$ & $\begin{array}{l}\mathrm{HCl} \\
\text { vol. }\end{array}$ & $\mathrm{HF}$ & $\begin{array}{c}\text { HF } \\
\text { Mass }\end{array}$ & $\mathrm{HCl}$ & $\begin{array}{l}\mathrm{HCl} \\
\text { vol. }\end{array}$ \\
\hline & & (M) & (ml) & $(\%)$ & (g) & (M) & (ml) \\
\hline Chongqing & 100 & 5.00 & 208 & 40.0 & 208 & 5.00 & 208 \\
\hline Furong & 100 & 5.00 & 433 & 40.0 & 433 & 5.00 & 433 \\
\hline
\end{tabular}

Table 3: $\quad$ Analytical results of ash free coal samples.

\begin{tabular}{|c|c|c|c|c|c|c|c|c|}
\hline \multirow{2}{*}{$\begin{array}{c}\text { Coal } \\
\text { sample }\end{array}$} & \multicolumn{4}{|c|}{ Rawcoal } & \multicolumn{4}{|c|}{ Ash free coal } \\
\hline & Ash & M & VM & $\mathrm{FC}$ & Ash & M & VM & $\mathrm{FC}$ \\
\hline Chongqing & 11.9 & 2.4 & 18.9 & 66.8 & 0.8 & 2.4 & 19.0 & 77.8 \\
\hline Furong & 24.8 & 3.1 & 15.2 & 56.9 & 3.0 & 3.1 & 13.2 & 80.7 \\
\hline Adaro & 3.3 & 9.3 & 45.7 & 41.7 & - & - & - & - \\
\hline
\end{tabular}




\subsection{Analysis of chemical structure of carbonaceous content using Fourier-transform infrared spectrometry}

In order to qualitatively investigate the chemical structure of carbonaceous content in different grade coal samples based on the Fourier-transform infrared spectrometry (FT-IR), the infrared spectra was recorded using a Model IR-6100 (Jasco Corporation, Japan) interfaced to a personal computer operating with Windows based spectra manager (Version 2). Firstly, ash free coal samples were sufficiently ground and mixed with $\mathrm{KBr}$ in the proportion of coal and $\mathrm{KBr}$, 1:200. Mixtures were molded into a $5 \mathrm{~mm} \varphi$ pellet, formed to the sample tablet. All pellets were dried at $107^{\circ} \mathrm{C}$ for 15 minutes in order not to be affected by moisture in the air. The spectra were recorded from 4,000 to $400 \mathrm{~cm}^{-1}$, the number of scans being 256 at the resolution of $4 \mathrm{~cm}^{-1}$. But carbonaceous content in coals have a lot of functions [10], so some recorded spectra go over with respect to one another. For precise evaluation on the chemical structure of each coal, we focus our attention on and looked for function groups containing oxygenic content, aliphatic $\mathrm{CH}$, and aromatic $\mathrm{CH}$ in order to resolve the problem. Table 4 explains the principal functional groups observed in the spectra. For background measurement, about $1 \mathrm{mg}$ of ground $\mathrm{KBr}$ was molded into a $5 \mathrm{~mm} \varphi$ pellet, formed to a $\mathrm{KBr}$ tablet and in the same way measurement was conducted.

Table 4: Absorption bands of functional groups of carbonaceous content in coal usually observed in the FT-IR spectra.

\begin{tabular}{cl}
\hline $\begin{array}{c}\text { Absorption bands of } \\
\text { function groups }\left(\mathrm{cm}^{-1}\right)\end{array}$ & Assignment (Function groups and their vibrations) \\
\hline 3,390 & Stretching vibrations O-H group and -OH groups \\
3,046 & Aromatic C-H groups \\
2,921 & Asymmetric C-H stretching vibra tions of aliphatic groups \\
2,853 & symmetric C-H stretching vibrations of aliphatic groups \\
1,698 & COOH groups \\
1,603 & Highly conjugated C=O groups \\
$875 \sim 750$ & Aromatic C-H groups \\
\hline
\end{tabular}

\subsection{Oil agglomeration experiments}

The schematic diagram of a procedure of oil agglomeration is shown in figure 2; experimental conditions are given in table 5. Firstly, tap water and the ash free coal was poured into a $500 \mathrm{~mL}$ beaker and mixed. After the mixture became a suspension, kerosene or vegetable oil as an aggregating agent was poured in the beaker and the aggregate was formed. When it was steady, the agglomerates in the water were filtered with $75,150,250,500 \mu \mathrm{m}$ sieving in order to investigate the growth of agglomeration, which presents that agglomerates were classified at every particle size. The agglomerates were filtered and dried overnight at room temperature, washed with ethanol and diethyl ether to remove oils in 


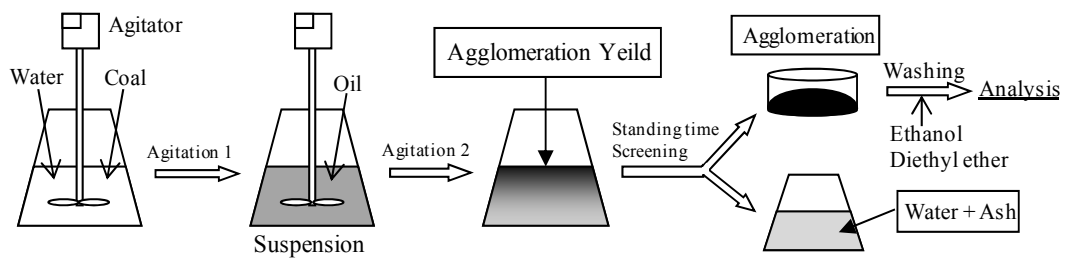

Figure 2: $\quad$ Schematic diagram for steps of oil agglomeration experiment.

Table 5: $\quad$ Experimental conditions of oil agglomeration with ash free coals.

\begin{tabular}{c|c}
\hline Item & Experimental conditions \\
\hline Sample & Ash free coal: $5.00 \mathrm{~g}$ \\
Water & $200 \mathrm{~mL}$ \\
Oil & $1.00 \mathrm{~g}$ \\
Agitation 1 & Time $: 3 \mathrm{~min}$, Speed $: 1,000 \mathrm{rpm}$ \\
Agitation 2 & Time : $3 \mathrm{~min}$, Speed $: 1,000 \mathrm{rpm}$ \\
Standing time & $3 \mathrm{~min}$ \\
\hline
\end{tabular}

agglomeration, dried overnight at room temperature again $[5,6]$. Actually, on the industrial application, solvent washing steps of agglomerates would not be necessary and coal/oil agglomerates could be used directly as fuel because there were fewer pollutants in the oils. For the evaluation of experiments, we measured the weight of recovered agglomeration of every particle size and residual oils which attached to the carbonaceous content in the following equations (1) and (2). The former is the ratios of particle size of agglomerations which indicate the growth of the agglomerates. The latter is the ratios of oil adhesion which indicate the mass of oils used in the agglomerate process and increasing of this value means that it is easy for oil to attach to the surface of carbonaceous content. The oil adhesion is calculated by the weight difference when oil in agglomeration is washed with organic solvent. Moreover, it is used only with vegetable oil because kerosene vaporizes while drying.

$$
\begin{gathered}
\text { Ratio of agglomeration size }(\%)=\frac{w t_{\mathrm{X} \mu \mathrm{m} \text { agglom }}(\mathrm{g})}{w t_{\text {agglom }}(\mathrm{g})} \times 100 \\
\text { Oil adhesion }(\%)=\frac{w t_{1}(\mathrm{~g})-w t_{2}(\mathrm{~g})}{w t_{\text {accretive oil }}(\mathrm{g})} \times 100
\end{gathered}
$$

In formula, agglom means recovered agglomeration, $w t$ gives the weight unit (g). On ratio of agglomeration size, $\mathrm{X}$ indicates $>500,500-250,250-150,150$ $75 \mu \mathrm{m}$ respectively, where $w t \times \mu \mathrm{m}$ agglom means the weight of agglomeration recovered by each sieving. On oil adhesion, $w t_{1}$ is the weight of agglomeration before washing oil and $w t_{2}$ is the weight of agglomeration after washing oil, $w t_{\text {accretive oil }}$ is about $1.00 \mathrm{~g}$ from table 5 . 
Actually waste coals contain large amounts of ash content, but in the case of oil agglomeration with ash free coals, this does not reappear. Consequently, as a sample we used the mixture of $5.00 \mathrm{~g}$ ash free coals and $5.00 \mathrm{~g}$ model ash which is combustion ash of coal, conducted the oil agglomeration similarly to the procedure of experiment in section 2.4. When sieving in water, the resultant agglomerate products were separated from ash content below $75 \mu \mathrm{m}$ sieving. In recovered agglomeration every particle size was gathered and analyzed for ash content. The efficiencies of coal cleaning were calculated by the percentages (wt.\%) of combustible matter recovery $(C M R)$, ash reduction $(A R)$ and efficiency index $(E I)$ from ash content in cleaned coal $[3,5]$. These parameters can be calculated as the following equations (3)-(5), where $C M$ is 100- (ash content), feed is the weight of coal sample, respectively.

$$
\begin{gathered}
C M R(\%)=\frac{C M_{\text {agglom }}(\mathrm{wt} . \%) \times w t_{\text {agglom }}(\mathrm{g})}{C M_{\text {feed }}(\mathrm{wt} . \%) \times w t_{\text {feed }}(\mathrm{g})} \times 100 \\
A R(\%)=100-\frac{A s h_{\text {agglom }}(\mathrm{wt} . \%) \times w t_{\text {agglom }}(\mathrm{g})}{A s h_{\text {feed }}(\mathrm{wt} . \%) \times w t_{\text {feed }}(\mathrm{g})} \times 100 \\
E I(\%)=C M R(\%)+A R(\%)
\end{gathered}
$$

\section{Results and discussion}

\subsection{FT-IR spectra of ash free coal sample}

The FT-IR spectra of ash free coal samples are presented in figure 3. The absorption at $3,390 \mathrm{~cm}^{-1}$ is assigned to the stretching vibration of $-\mathrm{OH}$ and $\mathrm{O}-\mathrm{H}$ groups, the absorption at $1,603 \mathrm{~cm}^{-1}$ is due to the highly conjugated $\mathrm{C}=\mathrm{O}$ groups $[9,10]$. As many oxygenic function groups exist in coal samples, these two peaks pronouncedly become strong. Also, the peak of the $\mathrm{COOH}$ group is only observed at $1,700 \mathrm{~cm}^{-1}$ on the Adaro ash free coal because of many oxygenic function groups. As a result, the surface feature of Adaro ash free coal is the

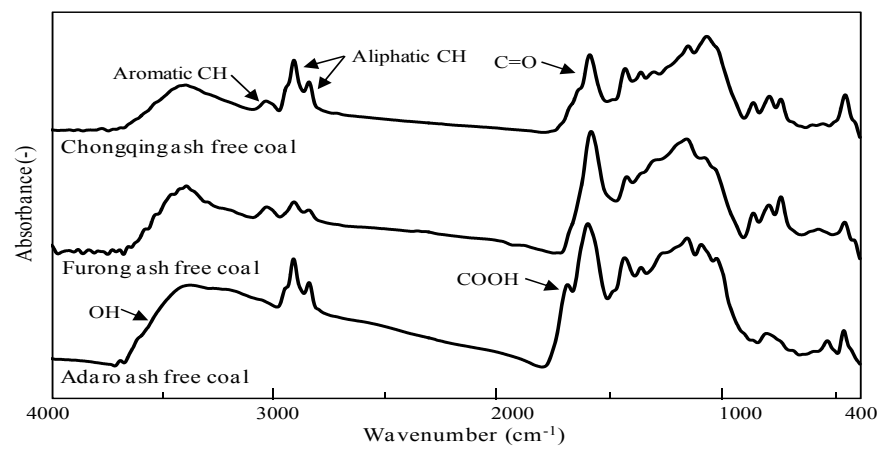

Figure 3: $\quad$ FT-IR spectra of three kinds of ash free coal samples. 
most hydrophilic than other coal samples. The $\mathrm{C}=\mathrm{O}$ groups appear in each coal sample, we think that it is affected by $\mathrm{CO}_{2}$ in the air.

Aliphatic groups are observed at $2,921 \mathrm{~cm}^{-1}$ as the asymmetric $\mathrm{C}-\mathrm{H}$ stretching vibrations and at $2,853 \mathrm{~cm}^{-1}$ as the symmetric $\mathrm{C}-\mathrm{H}$ stretching vibrations. For low grade, Adaro ash free coal has many aliphatic groups. Aromatic $\mathrm{C}-\mathrm{H}$ groups at $2,853 \mathrm{~cm}^{-1}$ are assigned from the inflexion point and this peak is usually small and not well defined [10]. But this peak of Furong ash free coal is clear and notable, accordingly Furong ash free coal has the highest rank of coalification. Against all expectations, Chongqing ash free coal which has a lot of carbon content and less oxygenic content did not develop the coalification.

\subsection{Results of oil agglomeration experiments with ash free coals}

Figure 4 shows the results of oil agglomeration experiments with ash free coals. This result means characteristics of agglomeration and intention of forming the aggregate. Focusing our attention on oxygenic function groups, aromatic/ aliphatic groups and oil structures, these results are considered.

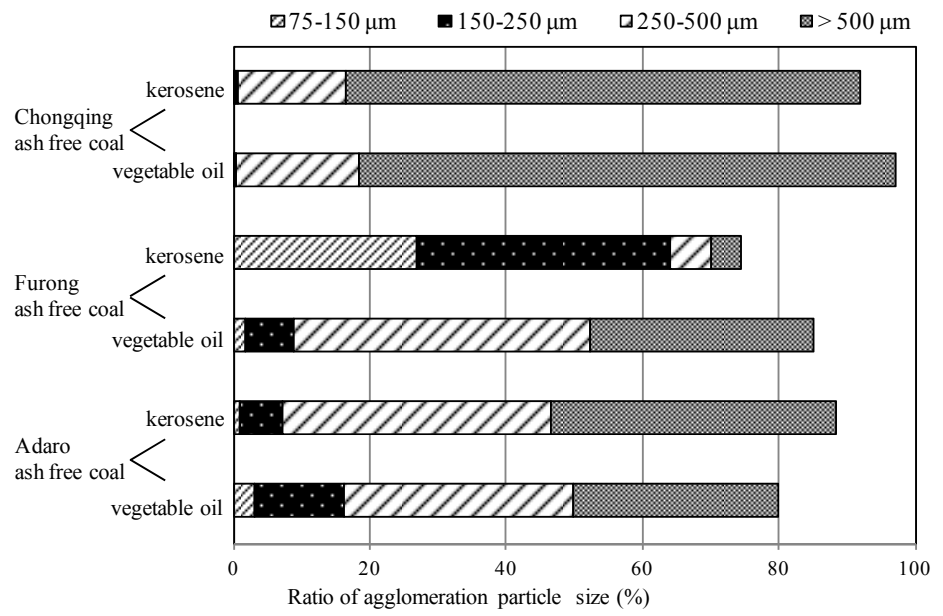

Figure 4: Particle size distribution of aggregate on oil agglomeration experiment with ash free coals.

\subsection{Inhibition of oil attachment on oxygenic content}

The computational results of oil adhesion which is the amount of oil comprised in the agglomeration show that Chongqing ash free coal $93.1 \%>$ Furong ash free coal $75.6 \%>$ Adaro ash free coal $69.8 \%$. The more carbonaceous content has oxygenic function groups, the less the oil attaches on the carbonaceous surface, which in other words means the hydrophilic function groups prevent the hydrophobic oil from adhering on the carbonaceous content [11].

In figure 4, the agglomeration of Chongqing ash free coal which many oils attach grows than any other coal samples, and the particle size ratio of $>500 \mu \mathrm{m}$ 
agglomeration occupied most of them. On the other hand, Furong and Adaro ash free coals where less oil attaches do not grow by comparison. From these results, we think that there are many hydrophilic functional groups in carbonaceous content causing the inhibition of oil attaching, which the coal many oils adhere to forms a larger agglomeration and may be easy to be recovered.

\subsubsection{Effect of aromatic and aliphatic groups}

In general, being graphite of the coal generates the resonance inspection of delocalized $\pi$ electron. The charge delocalization in the carbonaceous structure especially aromatic groups makes its surface less bias of the charge, where the coal becomes stabilizing. Meanwhile, aliphatic groups and oil have a little dipole moment, both are easy not only to cause the hydrophobic interaction or the dipole-dipole interaction, but also oil agglomeration comparatively.

Drawing a comparison between the agglomeration of Furong and Adaro ash free coal which are to be grown less, Adaro ash free coal slightly forms bigger agglomerations because there are large amounts of aliphatic groups in Adaro ash free coal. We think that some coals like Furong ash free coal becoming graphite do not go well together between coal and oil.

\subsubsection{Differences between structure of oil types}

Kerosene consisted of the aliphatic groups only and vegetable oil has some oxygenic content. Normally oxygenic content may degrade the coal cleaning efficiency but it depends on the combination of coals and oil. It reported that the hydrophilic oxygenic content in vegetable oil, such as the free fatty acid or the aldehyde group play the role of the bridging material to oxygenic function groups in carbonaceous content $[5,6]$. On the oil agglomeration of Furong ash free coal with kerosene, the particle size of agglomeration is considerably smaller than other conditions. It occurs because the aromatic groups of Furong ash free coal and the aliphatic groups of the kerosene interact badly. However, in the experiments with the vegetable oil, it is improved because the oxygenic content of Furong ash free coal and vegetable oil may interact with each other conscientiously.

\subsection{Results of oil agglomeration experiments imitated waste coals}

The results of oil agglomeration experiments simulated waste coal are explained in figures 5 and 6 .

\subsubsection{Factors affecting recovery of combustible matter}

The agglomerated behavior of each grade coal is similar to figure 4, but the agglomeration of Furong and Adaro mixed samples do not grow so much due to the ash content in the suspension. Ash content may avoid carbonaceous content and oil form interference and forming the aggregate, in the case of Furong and Adaro mixed samples, the poor action of agglutinating makes it contribute. Therefore, CMR of two coals is low. In addition, the ratio of oil adhesion may have a relationship with $C M R$. Comparing the experiments with only ash free coal, oil adhesion of the Chongqing mixed sample shows a similar value, $90.2 \%$, but that of Furong and Adaro mixed samples turn into 55.4\% from 75.6\%, 35.4\% 


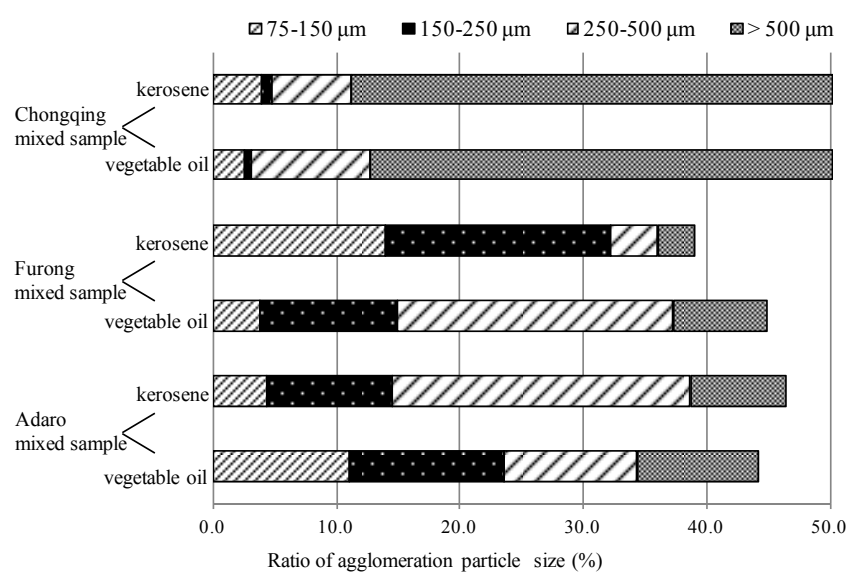

Figure 5: Particle size distribution of aggregate in oil agglomeration experiment with mixed coal sample of simulated waste coals.

from $69.8 \%$ respectively. The existence of ash content in suspension not only makes the selectivity property but also CMR lowering.

\subsubsection{Reason of the decreasing ash reduction}

The coal which is easy to forming the bulky aggregate like the Chongqing mixed sample shows higher $C M R$, but on its agglomerating way there is concern that ash content is taken into the aggregate. Therefore, $A R$ of the Chongqing mixed sample is a little lower than other coal samples.

$A R$ of Adaro mixed sample is low also, which it is thought to be the reason for the interactions between ash and oxygenic content which have hydrophilic property either [12]. We could visually make sure that the ash content which indicates red was comprised in the $75 \sim 150 \mu \mathrm{m}$ aggregate, and then on the earlier stage of agglomeration, both are attached and it stop growing bulky agglomeration.

\subsubsection{Evaluation of coal cleaning efficiency}

From these two experiments, the coal composed of a lot of carbon content tends to achieve good coal cleaning efficiency because there is little negative factor such as oxygenic content in coals. Taking into account of the results of oil agglomeration of the Furong and Adaro coal, the combination of aliphatic or aromatic groups of coal and oil may be the important factor of oil agglomeration. In other words, even though low grade coal has less carbon content, we can sufficiently recover it by finding out the optimum conditions. 


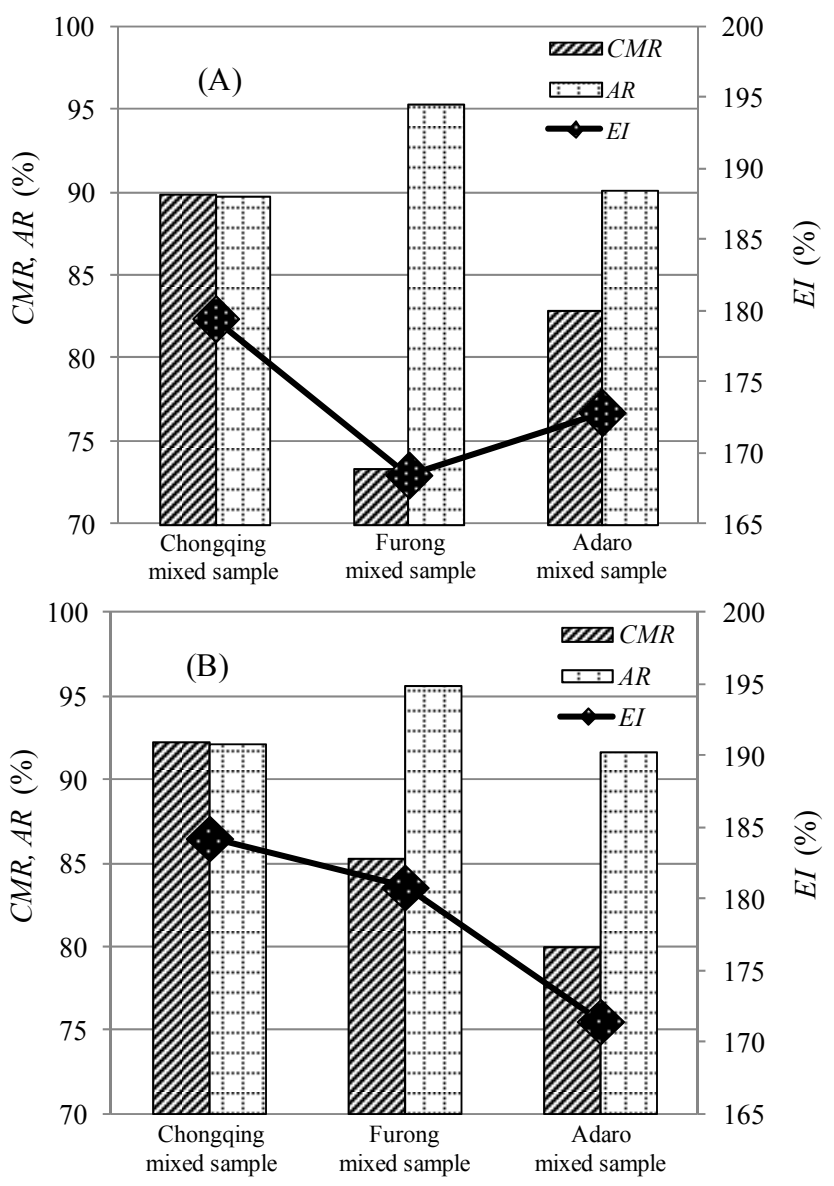

Figure 6: Comparison of coal cleaning efficiency of oil agglomeration simulated waste coal, (A) with kerosene and (B) with vegetable oil.

\section{Conclusion}

In this study, we investigated influential factors on the oil agglomeration process for coal recovery and found that there are some parameters which can be applied. Oxygenic functional groups in carbonaceous content prevent oil from attaching to the carbonaceous surface and forming the bulky aggregate. Therefore, it leads to depress $C M R$ and $E I$. It can be improved by changing oil types. Oxygenic content in oil such as vegetable oil play the role of the bridging material to the oxygenic functional groups in carbonaceous content, which may improve the coal cleaning efficiency of certain grade coals. Aromatic groups in carbonaceous content have the resonance inspection of delocalized $\pi$ electron, it interacts badly to aliphatic groups in oil, comparatively the carbonaceous content consisted of more aliphatic groups tends to form the aggregate easily. 


\section{Acknowledgement}

Some works of this study were supported by the special funds for Basic Researches (B) (No. 22404022, FY2010 2012) of Grant-in-Aid for Scientific Research of the Japanese Ministry of Education, Culture, Sports, Science and Technology (MEXT), Japan.

\section{References}

[1] World Energy Outlook 2007 - China’s Energy Prospects, ISBN: 978-9264-02730-5, IEA.

[2] A.F. Valdes, and B. Garcia, On the utilization of waste vegetable oils (WVO) as agglomerants to recover coal from coal fines cleaning waste (CFCW), Fuel, 85, 607-614, 2006.

[3] M.I. Alonso, A.F. Valdes, R.M. Martinez-Tarazona, and B. Garcia, Coal recovery from coal fines cleaning wastes by agglomeration with vegetable oils: effects of oil type and concentration, Fuel, 78, 753-759, 1999.

[4] A. Gurses, K. Doymus, and S. Bayrakceken, Selective oil agglomeration of brown coal: a systematic investigation of the design and process variables in the conditioning step, Fuel, 75, 1175-1 180, 1996.

[5] Q. Wang, N. Kashiwagi, P. Apaer, Q. Chen, Y. Wang, and T. Maezono, Study on coal recovery technology from waste fine Chinese coals by a vegetable oil agglomeration process, The Sustainable World, 142, 331-342, 2010.

[6] Q. Wang, N. Kashiwagi, P. Apaer, Q. Chen, Y. Wang, T. Maezono, and D. Niida, Recovery of combustible matter from waste fine Chinese coals by a waste vegetable oil agglomerating process and its combustion characteristics, Energy and Sustainability, 143, 327-338, 2011.

[7] A. Gurses, K. Doymus, and S. Bayrakceken, Evaluation of response of brown coal to selective oil agglomeration by zeta potential measurements of the agglomerates, Fuel, 76, 1439-1444, 1997.

[8] J. Krysyna, and C.J. Barend, Relating coal oxidation and hydrophobicity: a petrographic approach, Fuel, 75, 1611-1616, 1996.

[9] C.A. Strydom, J.R. Bunt, H.H. Schobert, and M. Raghoo, Changes to the organic functional groups of an inertinite rich medium rank bituminous coal during acid treatment processes, Fuel Processing Technology 92, 764-770, 2011.

[10] W. Geng, T. Nakajima, H. Takanashi, and A. Ohki, Analysis of carboxyl group in coal and coal aromaticity by Fourier transform infrared (FT-IR) spectrometry, Fuel, 88, 139-144, 2009.

[11] D. Das, U. Dash, A. Nayk, and P.K. Misra, Surface Engineering of Low Rank Indian Coals by Starch - Based Additives for the Formulation of Concentrated Coal - Water Slurry, Energy Fuels, 24, 1260-1268, 2010.

[12] A. Ozkan, H. Ucbetiay, and S. Duzyol, Comparison of stages in oil agglomeration process of quartz with sodium oleate in the presence $\mathrm{Ca}$ and Mg ions, Journal of Colloid and Interface Science, 329, 81-88, 2009. 